\title{
Countermeasure drowsiness by design - using common behaviour
}

\author{
Staffan Davidsson ${ }^{\mathrm{a}}$ \\ ${ }^{a}$ Luleå University of technology, Sweden and Volvo Cars Corporation,
}

\begin{abstract}
This study takes a starting point in what drivers do to avoid drowsiness while driving instead of starting with what researchers know is efficient (Take a short nap). It is concluded that research is missing when it comes to how efficient common behavior countermeasures are and that there is a mismatch between research and how people actually behave. A three stage approach which includes identification, information and countermeasure is suggested. Furthermore are a few ideas of what car manufacturers can do to support human behavior presented.
\end{abstract}

Keywords: Tiredness, drowsiness, countermeasures, system design

\section{Introduction}

\subsection{Background}

The lowest figures in accident statistics about how many accidents are caused by drivers falling asleep begins at 1-3 percent [1-3]. Other scientific estimates show a lot higher figures, $10-30$ per cent [4-8]. Regardless of which figure is true, a lot of people get killed every year due to drowsiness.

The research focus has so far been on reason for and the detection of sleepiness and there are just a few research articles that addresses the countermeasures $[9,10]$. However, some of the car manufacturers have designed warning system that warns the driver if it is indicated that the driver is drowsy. One example is Volvo Cars that introduced a system called Driver Alert. This system shows a coffee cup and ask/suggest the driver "Time for a brake" if it is indicated that the driver is in-alert.

This may be a correct countermeasure. Almost all experts agree on that the only truly effective strategy drowsy drivers can take to prevent a crash is to immediately stop driving and get some sleep.

According to for instance [9] is "Letting someone else drive for 1-2 hours while you sleep in the passenger seat before driving again" and "Pulling off road to take a 30-45 minute nap" the most certain behaviours that will result in increased alertness in a drowsy/sleepy driver.

If this is not possible, drivers should be encouraged to stop and drink some caffeine [11].

The first question that is addressed in this paper is if people act accordingly to this research?

The second question the author would like to address is the suspicion that people take other actions than what researchers recommend. They simply continue to drive.

One reason for not stopping and take a nap may be that the drivers either, do not feel drowsy or do not recognize or admit their feelings of drowsiness [8].

There may also be other countermeasures or strategies that drivers typically employ - rolling down the car windows, turning up the radio, stopping to stretch - However, these are largely unsupported by the scientific literature. The motivation to reach the goal may be more important than to drive safely. Drivers think. "I can handle this." This bias is confirmed by occasions where they have been drowsy but still managed to arrive safely at their destinations [8].

So, what do we do? People get killed when they fall asleep, researchers know what to do to but drivers continue to drive. The third question in this paper is therefore if it is possible to learn from common, anecdotal or not, behaviour and develop highly ac- 
cepted or even enjoyable vehicle systems that are used and can keep the driver alert.

For instance, a hopeful and recent study [13] demonstrated that a motivating cognitive stimulation while driving has the potential to suppress fatigue symptoms caused by underload driving conditions. Interactive cognitive tasks (ICTs) can play a role in eliminating hazardous situations caused by underload. Another study [14] confirms that this may be a mean to avoid performance decrement but associate it with a cost.

Furthermore, a study [16] that used pre-loading tasks to move mental demand from high demand situations to situations where there is low demand in order to avoid decrement of performance, indicate promising effect.

The efficiency of the means will not be investigated further in this study but opens up for further research.

\section{Method}

\subsection{Tools}

A small pilot study was performed to get as many action options as possible to choose from. 14 different activities were identified. An Internet survey was created in the tool "Surveymesh" (www.surveymesh.se). The survey contained background question about gender, age, years holding a driving license and how many kilometers they drove per year.

The subjects were then given the opportunity to choose one or several of the 14 actions that they use to do if they felt tired. Then they were asked if there activity worked, how often they used the activity, on which road type they easiest get tired, after how long time and at which time they get tired. The exact wording can be seen in the result part. The participant got the possibility to give multiple choices when necessary.

The subjects were recruited from different social media such as Facebook.

The different options presented were not randomly varied due to limitations of the "Surveymesh" tool. After looking into the survey figures a brain storm session took place, giving suggestions on how to use the common behavior in system design. These suggestions are not included in the result part but some examples are shown in the discussion.

\subsection{Subjects}

The survey was completed by 44 ( 59.5 per cent) men and 33 (40.5 per cent) women. The average age among the participants was M: 44.5 years, SD: 9,4 . The number of years with a driving license was in average M: 25.6 years, SD: 9,5. 52.7 per cent drove between 10000 to $20000 \mathrm{~km}, 24.3$ per cent drove less than $10000 \mathrm{~km}, 17.6$ per cent drove between 20000 and $30000 \mathrm{~km}$ and only 5.4 per cent drove more than $30000 \mathrm{~km}$ per year. The survey was in Swedish why all of the subjects know Swedish.

\section{Result}

The result of the study is presented in the tables below.

What do you do when you drive and start to feel tired?

\begin{tabular}{|lll}
\hline Activity & $\begin{array}{c}\text { Num- } \\
\text { ber }\end{array}$ & $\%$ \\
\hline Change seating position & 45 & 16.1 \\
\hline Pull over and get some fresh air & 37 & 13.3 \\
\hline Increase the fan and reduce temperature & 36 & 12.9 \\
\hline Play loud music & 30 & 10.8 \\
\hline Open the side window & 27 & 9.7 \\
\hline Talk to passengers & 25 & 9.0 \\
\hline Drink Coffee & 25 & 9.0 \\
\hline Sing & 19 & 6 \\
\hline Listen to people talking or discussing on the radio & 17 & 6.1 \\
\hline
\end{tabular}




\begin{tabular}{lll}
\hline Pull over and sleep & 3 & 3.2 \\
\hline Talk in the phone & 5 & 1.8 \\
\hline Play "car games" e.g. count red cars or count numbers on registration plate... & 2 \\
\hline Look at the nature & 0.7 & 2 \\
\hline Write and read SMS (Text messages) & 0 \\
\hline
\end{tabular}

Table 2.

Do you experience that your activity work?

\begin{tabular}{|c|c|c|}
\hline Grade & $\begin{array}{l}\text { Num- } \\
\text { ber }\end{array}$ & $\%$ \\
\hline $1=$ Not at all & 0 & 0 \\
\hline 2 & 2 & 3 \\
\hline 3 & 9 & 12 \\
\hline 4 & 21 & 28 \\
\hline 5 & 28 & 38 \\
\hline 6 & 12 & 16 \\
\hline $7=$ Yes, a lot & 2 & 3 \\
\hline Average & & 4.6 \\
\hline
\end{tabular}

Table 3.

How often do you use these activities?

\begin{tabular}{|c|c|c|}
\hline How often & $\begin{array}{l}\text { Num- } \\
\text { ber }\end{array}$ & $\%$ \\
\hline A few times every year & 38 & 52.1 \\
\hline A few times every month & 19 & 26.0 \\
\hline Very seldom ( $<$ once a year) & 14 & 19.2 \\
\hline Dayly & 1 & 1.4 \\
\hline A few times every week & 1 & 1.4 \\
\hline
\end{tabular}

Table 4.

On which road types do you easiest get tired?

\begin{tabular}{lcc}
\hline Road type & Number & \% \\
\hline Motor way & 65 & 67.9 \\
\hline Highway (Rural road) & 30.9 & 25 \\
\hline City road & 1.2 \\
\hline
\end{tabular}

Table 5.

After how long drive do you use to get tired?

\begin{tabular}{lcc}
\hline After how long drive do you use to get tired? & Number & \% \\
\hline $3-4$ hours & 26 & 32.5 \\
\hline $1-2$ hours & 23 & 28.8 \\
\hline 30 minutes - 1 hour & 17.5 & 14 \\
\hline
\end{tabular}




\begin{tabular}{lrr}
\hline$>4$ hours & 13 & 16.2 \\
\hline$<30$ minutes & 5.0 & 4 \\
\hline Never & 0 & 0 \\
\hline
\end{tabular}

Table 6 .

At which time do you get tired?

\begin{tabular}{|c|c|c|}
\hline At which time do you get tired? & Number & $\%$ \\
\hline Evening & 40 & 36.4 \\
\hline Afternoon (pm) & 31 & 28.2 \\
\hline Night & 31 & 28.2 \\
\hline Morning & 6 & 5.5 \\
\hline Noon & 2 & 1.8 \\
\hline Before Noon (am) & 0 & 0 \\
\hline
\end{tabular}

\section{Conclusion and Discussion}

\subsection{Mismatch}

Regardless of the knowledge among researchers do not very many "ordinary" drivers pull over and sleep when they get tired. Only 3.2 per cent of the participants use this activity when tired. Instead seems physical changes be the most common activity. The physical changes "Change seating position", "Pull over and get some fresh air", "Increase the fan and reduce the temperature" and "Open the side window" represented half of the answers.

Experts believe that these activities work moderately. It is therefore clear mismatches between what drivers in this survey do and what is accepted as efficient in the research community.

Interestingly is the number of activities that can be classified as cognitive not very high. For instance, was "Listen to people talking or discussing on the radio " and "Talk in the phone" only used by 6.1 and 1.8 percent respectively, of the participants. It should be mentioned that talking in mobile phone is not prohibited in Sweden.

On the other hand may "Talk to passengers" be included in this group of activities and this represents 9 per cent of the activities. Verbal conversation also seems to be one way to reduce drowsiness even if the effect only last for a limited period of time [12].

Luckily, does not anyone in the survey use texting (SMS) as a mean to avoid falling asleep. It has been shown that text messages increases risk for accident twenty three times when texting while driving [17].
It seems that most of the subjects are fairly satisfied with the result of their strategy to cope with tiredness. One interesting question that has to be raised is if the participants in this study are wrong or if their activities actually work?

Is their behavior only based on misleading confirmation bias or are the current methodology insensitive for these types of activities?

If the methodology is only sensitive to what really works, drivers are wrong and we have to continue as today, working out information and warning campaigns. If the methodology is in-sensitive and the activities actually work is it perhaps possible to develop well accepted systems or services that help drivers to stay alert.

Today some car manufacturers provide warnings or information about that the driver may be tired. However, the car does not provide any help to reduce tiredness. In a future system can other validated functions hopefully also get the driver other countermeasures to fight tiredness.

\subsection{Three stages to support driver}

It can be suggested that to avoid tiredness while driving three stages are needed:

1. Identify tiredness: improve sensitivity in the measurement of tiredness by using available map data, time and driving hours. Most of the tiredness occurred on the motorway, after 1 hour and in the early morning and the late afternoon. "Driving hours" and at "which time" it is most likely to get tired has also been confirmed in for instance [14]. 
2. Inform or warn about tiredness. Suggest countermeasures.

3. Provide means based on activities drivers perform today to avoid tiredness. The car suggest countermeasures such as:

- Automatic seat adjustment/movement. The seat starts, on request, to move slowly after some hours.

- Lower temperature and increase fan automatically when there are indications of poor alertness.

- Suggest a coffee brake.

- To sing seems is both fairly efficient according to the experts in [9] and used in 6 percent of the answer. Can a Karaoke activity without the text row be efficient?

- $\quad$ Not very many play "car games" while driving and the experts seem to not find it very efficient. However, the research [13] shows different result and if it is correctly designed to not distract it may be useful.

\subsection{Limitations}

Recruitment through the social media is extremely convenient. However, the control over the respondents answering the questionnaire is of course limited. In this study the main idea was to identify different activities and give a rough figure what drivers do when they get tired. It was not important if "Pull over and sleep" was more common than for instance "Playing car games".

An effect of the poor control of the participants was that the average age was higher than expected. This may have a large impact on the result since younger drivers are over-represented in the drowsiness crash statistics [15].

The small pilot study identified a lot of different activities. However, some may have been forgotten and therefore not quantified. One such activity was "Increase speed" which afterwards, in the free text was found to be an activity used by some drivers. Future studies can quantify how common this activity is to improve alertness and if it is useful.

\subsection{Further research}

As mentioned earlier is this study only a start. More participants with a more complete age profile and different cultural background must be involved in future studies.

It would also be interesting to go further in the analysis. For example, for those first 5 actions, that most people apply, would they work better than the other actions? Another question could be how drivers combine these activities and which effect that might give.

From a methodological perspective may a more naturalistic study sort out if these common activities work or not? Several other research questions can easily be identified now when the common behavior is given a chance.

\section{References}

[1] Larsson, J. \& Anund, A. (2002). Trötthet i trafiken. Studie av trötthetsrelaterade olyckor. Linköping: Statens väg- och transportforskningsinstitut. (VTI notat 34-2002.)

[2] Lisper, H. (1977). Trötthet i trafiken: En empiriskt och teoretisk översikt. Statens Offentliga Utredningar, SOU, 1977: 2, 229-284.

[3] Stutts, J., Wilkins, J., Osberg, S. \& Vaughn, B. (2003). Driver risk factors for sleep related crashes. Accident Analysis \& Prevention, 35, 321-331.

[4] Connor, J., Whitlock, G., Norton, R. \& Jackson, R. (2001). The role of driver sleepiness in car crashes: a systematic review of epidemiological studies Accident Analysis \& Prevention, 33(1), 31-41.

[5] Horne, J. \& Reyner, L. (1995). Falling asleep at the wheel. Crowthorne, Transport Research Laboratory. (TRL report 168).

[6] Horne, J. \& Reyner, L. (1995). Sleep related vehicle accidents. British Medical Journal, 310, 565-567.

[7] Maycock, G. (1997). Sleepiness and driving: The experience of U.K. car drivers. Accident Analysis \& Prevention, 29, 453462.

[8] Stutts, J., Wilkins, J. \& Vaughn, B. (1999). Why do people have drowsy driving crashes? Input from drivers who just did (No. 202/638-5944). Washington, D.C.: AAA Foundation for Traffic Safety.

[9] Nguyen, L. T., Jauregui, B., \& Dinges, D. F. (1998). Changing behavior to present drowsy driving and promote traffic safety: Review of proven, promising, and unproven techniques. Washington, DC: AAA Foundation for Traffic Safety.

[10] Oron-Gilad, T., Rönen. A., \& Shinar, D. (2008). Alertness maintaining tasks while driving. Accident Analysis and Prevention, $40,851-860$.

[11] The equivalent of NHTSA, 1998

[12] Schmidt, E. A., Schrauf, M., Simon, M., Buchner, A. \& Kincses, W. E. (2010). The short-term effect of verbally assessing drivers' state on vigilance indices during monotonous daytime driving Transportation Research Part F 14 (2011) 251-260

[13] Gershon, P., Ronen, A., Oron-Gilad, T., \& Shinar, D. (2009). The effects of an interactive cognitive task (ICT) in suppressing fatigue symptoms in driving. Transportation Research Part F, 12, 21-28.

[14] Atchley, P. \& Chan, M. (2010). Potential Benefits and Costs of Concurrent Task Engagement to Maintain Vigilance: A 
Driving Simulator Investigation Human Factors: The Journal of the Human Factors and Ergonomics Society

[15] Knipling, R. R., \& Wang, J. S. (1994). Crashes and fatalities related to driver drowsiness/fatigue, NHTSA Research Note. Washington, DC: National Highway Traffic Safety Administration.

[16] Young, M., Birrell, S., Davidsson, S. (2011). Task preloading: designing adaptive systems to counteract mental un- derload. Ergonomics and Human Factors Conference 2011, UK.

[17] Dingus, T. A., Klauer, S. G., Neale, V. L., Petersen, A., Lee, S. E., Sudweeks, J., et al. (2006). The 100-car naturalistic driving study, phase II - results of the 100-car field experiment (Technical Report No. DOT HS 810 593). Washington, DC: NHTSA. 